\title{
Dimensional Stability of Oriented Strand Boards with External Layers made of Non-Strand Chips: Changes in Board Length
}

\author{
Radosław Mirski, ${ }^{*}$ Dorota Dziurka, and Adam Derkowski \\ The dimensional stability of oriented strand boards (OSB) was evaluated \\ in terms of the changes in their length, static bending strength, and \\ modulus of elasticity. Outer layers of these boards were manufactured \\ from particles other than strand chips. The boards were exposed to an air \\ relative humidity of $30 \%, 65 \%$, or $85 \%$. Dimensional alterations were \\ determined separately for absorption (from 65\% to $85 \% \mathrm{RH}$ ) and \\ desorption (from $65 \%$ to $30 \% \mathrm{RH}$ ) changes. Changes in the mechanical \\ properties of the boards were evaluated after they underwent two cycles \\ of the conditioning process and were compared with the baseline values. \\ The study implied that relative changes in the mechanical properties and \\ length increased when there was a reduction in the size of chips that \\ formed the outer layers. A linear relationship was established between the \\ relative changes in the board length determined for the axis that was more \\ susceptible to deformation and the modulus of elasticity. These changes \\ were inversely proportional to the value of the modulus of elasticity.
}

Keywords: OSB; Flake; Chips; Dimensional stability; Humid conditions

Contact information: Poznań University of Life Sciences, Department of Wood-Based Materials, 28 Wojska Polskiego Str., 60-637 Poznań, Poland; *Corresponding author: rmirski@up.poznan.pl

\section{INTRODUCTION}

Oriented strand boards (OSB) are engineered materials designed for replacing plywood or solid wood in structural components. Thus, these boards must have excellent mechanical properties. To meet these requirements, high quality strips are used for their production, which can only be obtained by shredding wood material of high quality (Geimer et al. 1975; Mayers 2001). For this reason, production costs of these wood-based materials are relatively high. A method that is used to reduce production costs is a partial or complete substitution of wood strips with finer chips (Brinkmann 1979; Han et al. 2006; Mirski and Dziurka 2011a,b; Mirski et al. 2012). Despite a noticeable decrease in mechanical properties, particularly in the modulus of rigidity and modulus of elasticity, these boards meet the requirements specified in relevant standards (EN 300 2006).

The board durability, including its resistance to variable ambient conditions, depends on a binding agent. The resins typically used for OSB board production include phenol formaldehyde (PF), four component melamine-urea-phenol-formaldehyde resins (MUPF), and isocyanates (polymeric methylene diphenyl diisocyanate (pMDI)) (Avramidis and Smith 1989; Kim and Strickland 1994; Strickland 1994; Andersen and Troughton 1996; Kim and Watt 1996; Sellers 2001; Brochmann et al. 2004; Han et al. 2005; Semple et al. 2006; Gündüz et al. 2011). Additionally, wood-based materials can be preserved against environmental factors by an appropriate surface finish. However, due to the size of strips used in outer layers, surface treatments are used in the industry in strictly specified cases. When finer chips are used in outer layers with a core formed of typical 
wood strips, the boards are characterized by good physical properties, good mechanical properties, and a much smoother surface (Mirski et al. 2016). These findings are promising because a reduction in board production costs when using fine chips or by obtaining a smoother board surface can result in the deterioration of their physical properties and in dimensional changes when exposed to high and low humidity levels. Changes in air humidity change the moisture content of wood-based materials, leading to variability in their linear dimensions. For these reasons, numerous studies have examined the degree of resultant deformations and the relationship between these deformations and to a deterioration of mechanical properties or to production factors (Wu and Suchsland 1996; Wu and Piao 1999; Wu 1999; Wu and Lee 2002; Han et al. 2007).

This study determined the influence of the size (type) of chips used in an outer OSB layer on the degree of linear deformations in the board plane. Changes in mechanical properties after exposure to variations in humidity were determined by a bending test.

\section{EXPERIMENTAL}

The study used laboratory manufactured three-layer boards (ratio face/core 1:2) with the core layer made of industrial strand chips intended for the internal layer of OSB panels. The external layers were made of microchips (AA), fine chips (BB), average chips (CC), long chips (DD), and strand chips (EE) from pine wood (Pinus sylvestris L.). Detailed parameters of the chips used in the study were presented in a previous report (Mirski et al. 2016). In this study, similar markings were used. Due to the very good physical and mechanical properties obtained in the previous studies, the gluing level of chips in the outer layer was reduced. The chips were glued with pMDI (Bayer, Fribourg, Switzerland), and the reference boards were industrial OSB/3.glued in both layers with the same adhesive. The detailed conditions applied during board manufacturing are shown in Table 1. Each variant was manufactured with five replicates.

Table 1. Conditions for OSB Pressing

\begin{tabular}{|c|c|c|c|c|c|c|c|c|}
\hline \multicolumn{2}{|c|}{$\begin{array}{c}\text { RC/Wax Ratio } \\
(\%)\end{array}$} & \multicolumn{2}{c|}{$\begin{array}{c}\text { MC Chips } \\
(\%)\end{array}$} & Density & $\begin{array}{c}\text { Board } \\
\text { Thickness } \\
\left(\mathrm{kg} / \mathrm{m}^{3}\right)\end{array}$ & $\begin{array}{c}\text { Pressing } \\
\text { Time } \\
(\mathrm{s} / \mathrm{mm})\end{array}$ & $\begin{array}{c}\text { Pressing } \\
\text { Temperature } \\
\left({ }^{\circ} \mathrm{C}\right)\end{array}$ & $\begin{array}{c}\text { Unit } \\
\text { Pressure } \\
\left(\mathrm{N} / \mathrm{mm}^{2}\right)\end{array}$ \\
\hline Top & Core & Top & Core & & 15 & 15 & 200 & 2.5 \\
\hline $3 / 1.5$ & $3 / 1.5$ & 8.75 & 5.95 & 590 & 15 & & \\
\hline
\end{tabular}

Note: $\mathrm{RC}$ - resin content, $\mathrm{MC}$ - moisture content

The OSBs were tested against relevant standards for static bending strength, i.e., modulus of rigidity (MOR) and modulus of elasticity (MOE) according to EN 310 (1993) and for relative change in length according to EN 318 (2002).

Per EN 318 (2002), the samples of the tested material were divided into two sets. The first set was conditioned with the air relative humidity $(\mathrm{RH})$ gradually increasing from $30 \% \mathrm{RH}$ to $85 \% \mathrm{RH}$. The samples from the second set were placed in a chamber of $85 \%$ $\mathrm{RH}$, and the air humidity was gradually reduced to $30 \%$. An earlier study showed that the relative changes in the linear dimension after the third step of conditioning for Set 1 were larger than for Set 2, and with the increase in a number of cycles this relationship was associated with a number of times the studied material was exposed to extreme humidity levels. Furthermore, changes in the length of the minor axis could be twice as large for the major axis. Therefore, in this study, samples for both identified board axes were 
conditioned only using assumptions specified for Set 1 , while slowly increasing the RH from $20 \%$ to $85 \%$ and reducing the humidity to $20 \%$. Details of the conditioning process are shown in Table 2.

Table 2. Board Conditioning Process

\begin{tabular}{|c|c|c|c|}
\hline Step & Temperature and Relative Humidity & Step & Temperature and Relative Humidity \\
\hline 1 & $20^{\circ} \mathrm{C}, 20 \% \mathrm{RH}$ & $6^{* *}$ & $20^{\circ} \mathrm{C}, 65 \% \mathrm{RH}$ \\
\hline $2^{*}$ & $20^{\circ} \mathrm{C}, 30 \% \mathrm{RH}$ & 7 & $20^{\circ} \mathrm{C}, 45 \% \mathrm{RH}$ \\
\hline 3 & $20^{\circ} \mathrm{C}, 45 \% \mathrm{RH}$ & $8^{* *}$ & $20^{\circ} \mathrm{C}, 30 \% \mathrm{RH}$ \\
\hline $4^{*}$ & $20^{\circ} \mathrm{C}, 65 \% \mathrm{RH}$ & 9 & $20^{\circ} \mathrm{C}, 20 \% \mathrm{RH}$ \\
\hline 5 & $20^{\circ} \mathrm{C}, 85 \% \mathrm{RH}$ & 10 & $45^{\circ} \mathrm{C}, 20 \% \mathrm{RH}$ \\
\hline
\end{tabular}

Note: Steps specified in EN 318 (year) for $\left({ }^{*}\right)$ Set 1 and $\left({ }^{* *}\right)$ Set 2

The standard does not specify a history of humidity changes that should or should not characterize the material for which changes in linear dimensions are evaluated. Therefore, the proposed conditioning process encompassed both Set 1 (steps 2 through 5) and Set 2 (steps 5 through 8), according to EN 318 (2002). In the laboratory conditions, the moisture content of the boards after they were pressed was $2 \%$ to $3 \%$, which corresponded to the air relative humidity of $\mathrm{ca}$. $20 \%$. After the ninth conditioning step at $20{ }^{\circ} \mathrm{C}$, the average moisture content in the boards was $5.55 \%$ where $\mathrm{v}=7 \%$. Before evaluating the mechanical properties, the samples were conditioned at $45^{\circ} \mathrm{C}$ for four weeks to reach the baseline moisture content level of $c a .3 \%$.

Test samples of $350 \mathrm{~mm} \times 50 \mathrm{~mm} \times 15 \mathrm{~mm}$ were evaluated by the bending strength and the modulus of elasticity after the conditioning process. Twelve to eighteen samples were prepared for each type of board and axis. The samples were cut out along the longer side of the obtained sheet and perpendicular to the longer side. An axis for the samples obtained this way was determined according to a layout of wood strips in the core layer. Thus, similar to industrial OSB boards, the major axis was assigned to samples in which strips in the core layer were arranged perpendicular to the longer side of the sample, and the minor axis to their longitudinal arrangement.

Relative changes in length were calculated according to Eq. 1,

$$
\delta l_{x, y}=\frac{l_{y(n+1)}-l_{x n}}{l_{x n}} \times 1000[\mathrm{~mm} / \mathrm{m}]
$$

where $n$ is a conditioning step, $l_{x n}$ is the distance between measuring points for a given conditioning step, when necessary, adjusted taking into account marking used, in millimeters; $l_{y(n+1)}$ is the distance between measuring points for a given conditioning step one step above the reference level, when necessary, adjusted taking into account marking used, in millimeters; and $\delta l_{x, y}$ is the relevant change in the length for a change of the relative humidity from $\mathrm{X}$ to $\mathrm{Y}$, in millimeters per meter.

The moisture content of the boards was determined after each conditioning step by observing the changes in the weight of the same samples that were used for the evaluation of their linear dimensions and mechanical properties after conditioning. For this purpose, the dry weight of the boards to be conditioned and the weight of the samples after each conditioning step was determined. While determining the sample weight after each conditioning step is not difficult and does not affect its physical and mechanical properties, determining its dry weight requires complete removal of water from the sample. Such treatment, when conducted at a high temperature, is associated with a loss in the initial physical and mechanical properties of the studied material, which cannot be later used for 
further analyses. Therefore, the dry weight of half of the board samples was estimated directly after conditioning where randomly selected samples were dried in a laboratory oven at $103 \pm 1{ }^{\circ} \mathrm{C}$ for $48 \mathrm{~h}$ until their dry weight was reached. For the second half of the board samples, the dry weight was determined on a basis of the moisture content in the first half of samples, and the samples were used to evaluate the physical and mechanical properties. Statistical analyses were perfomed using Statistica 12 package (StatSoft Inc., Tulsa, OK, USA).

\section{RESULTS AND DISCUSSION}

The baseline values for the static bending strength and modulus of elasticity of the boards are presented in Tables 3 and 4 . The board consisted of sorted wood strips and was characterized by the highest strength and module of elasticity determined for the major axis. The static bending strength of this board was over 5.5 MPa higher than industrial OSB and over three times higher than a board with outer layers produced of AA. Furthermore, the modulus of elasticity of this board was over three times higher than the board containing the finest chips in its outer layers, but less than $15 \%$ higher than industrial OSB. A reduction in a treatment level of gluing of outer layers from 4\% (Mirski et al. 2016) to 3\% resulted in a decrease in the strength and the modulus of elasticity by a few to over twenty percent; as expected, larger changes were observed for boards produced from finer chips.

Table 3. Relative Changes in Static Bending Strength and Modulus of Elasticity in the Major Axis

\begin{tabular}{|c|c|c|c|c|c|c|c|c|c|}
\hline \multirow{2}{*}{$\begin{array}{c}\text { Board } \\
\text { Type }\end{array}$} & \multicolumn{2}{|c|}{$P^{\star}$} & \multicolumn{2}{|c|}{$K^{*}$} & \multirow{2}{*}{$\delta_{x}(\%)$} & \multirow{2}{*}{$\mathrm{t}$} & \multirow{2}{*}{$p$} & \multirow{2}{*}{$\begin{array}{l}\text { Levene's } \\
\text { F }(1, \mathrm{df})\end{array}$} & \multirow{2}{*}{$\begin{array}{c}p \\
\text { Levene's }\end{array}$} \\
\hline & {$\left[\mathrm{N} / \mathrm{mm}^{2}\right]$} & $v(\%)$ & $\left(\mathrm{N} / \mathrm{mm}^{2}\right)$ & $v(\%)$ & & & & & \\
\hline \multicolumn{10}{|c|}{ MOR } \\
\hline AA & 10.74 & 9.72 & 7.71 & 11.2 & 28.2 & 8.124 & 0.0000 & 0.0995 & 0.7551 \\
\hline BB & 12.37 & 7.61 & 10.31 & 12.8 & 16.7 & 4.503 & 0.0001 & \begin{tabular}{|l|}
2.7587 \\
\end{tabular} & 0.1097 \\
\hline $\mathrm{CC}$ & 14.42 & 7.14 & 11.92 & 14.1 & 17.3 & 4.482 & 0.0002 & 4.7796 & 0.0389 \\
\hline DD & 20.16 & 9.42 & 16.86 & 11.1 & 19.4 & 5.659 & 0.0000 & 0.4328 & 0.5169 \\
\hline EE & 32.48 & 12.2 & 26.83 & 12.8 & 17.4 & 3.901 & 0.0007 & 0.2561 & 0.6174 \\
\hline OSB & 26.94 & 10.2 & 20.75 & 13.8 & 23.0 & 5.693 & 0.0000 & 0.0040 & 0.9503 \\
\hline \multicolumn{10}{|c|}{ MOE } \\
\hline AA & 1638 & 8.46 & 1159 & 6.85 & 29.3 & 10.21 & 0.0000 & 1.3137 & 0.2630 \\
\hline $\mathrm{BB}$ & 2732 & 11.8 & 2036 & 8.98 & 25.5 & 6.894 & 0.0000 & 3.1096 & 0.0906 \\
\hline $\mathrm{CC}$ & 3146 & 4.29 & 2318 & 10.8 & 26.3 & 10.23 & 0.0000 & 6.2725 & 0.0195 \\
\hline DD & 4297 & 6.46 & 2837 & 8.49 & 19.3 & 5.353 & 0.0000 & 0.3999 & 0.5331 \\
\hline EE & 5294 & 11.0 & 4169 & 10.6 & 21.3 & 5.605 & 0.0000 & 2.0538 & 0.1647 \\
\hline OSB & 4733 & 8.78 & 4310 & 7.64 & 8.9 & 2.951 & 0.0068 & 1.0443 & 0.3166 \\
\hline
\end{tabular}

Furthermore, the conditioning process reduced the static bending strength and the modulus of elasticity regardless of a type of board or the axis considered. Concurrently, there was a much wider distribution of results within the analyzed group that was observed in the board minor axis than in the unconditioned boards of the same type. In consequence, differences between individual types of board were reduced, not only for the static bending strength, but also for modulus of elasticity. This effect was particularly true for boards containing finer chips in their outer layers. AA, BB, and CC boards were characterized by 
similar mechanical properties for their minor axis. However, in relation to the baseline values, regardless of the type of the board and analyzed axis, the values determined after the conditioning process for the static bending strength and for the modulus of elasticity were lower. They were significantly lower that the differences between the baseline and the final values were to be considered statistically significant. This conclusion was confirmed with a Student's t-test. In several cases the compared batches of the boards did not show statistically significant differences in their variances before and after the process (Levene's test), yet differences in the values before and after the process were high enough to be considered important from a practical point of view.

Table 4. Relative Changes in Static Bending Strength and Modulus of Elasticity in the Minor Axis

\begin{tabular}{|c|c|c|c|c|c|c|c|c|c|}
\hline \multirow{2}{*}{$\begin{array}{l}\text { Board } \\
\text { Type }\end{array}$} & \multicolumn{2}{|c|}{$P^{\star}$} & \multicolumn{2}{|c|}{$K^{*}$} & \multirow{2}{*}{$\delta_{x}(\%)$} & \multirow{2}{*}{$\mathrm{t}$} & \multirow[b]{2}{*}{$p$} & \multirow{2}{*}{$\begin{array}{l}\text { Levene's } \\
\text { F }(1, \mathrm{df})\end{array}$} & \multirow{2}{*}{$\begin{array}{c}p \\
\text { Levene's }\end{array}$} \\
\hline & $\left(\mathrm{N} / \mathrm{mm}^{2}\right)$ & $v(\%)$ & $\mathrm{N} / \mathrm{mm}^{2}$ & $v(\%)$ & & & & & \\
\hline \multicolumn{10}{|c|}{ MOR } \\
\hline AA & 15.94 & 8.12 & 12.09 & 11.2 & 24.2 & 7.354 & 0.0000 & 0.0385 & 0.8461 \\
\hline BB & 18.05 & 7.13 & 14.64 & 13.3 & 18.9 & 5.153 & 0.0000 & 1.4065 & 0.2472 \\
\hline $\mathrm{CC}$ & 19.55 & 7.19 & 16.90 & 10.8 & 13.6 & 4.082 & 0.0004 & 2.5171 & 0.1257 \\
\hline DD & 21.32 & 6.94 & 18.02 & 13.5 & 14.8 & 3.276 & 0.0032 & 0.2025 & 0.6568 \\
\hline $\mathrm{EE}$ & 23.12 & 10.5 & 20.62 & 12.9 & 10.8 & 2.492 & 0.0200 & 0.0245 & 0.8768 \\
\hline OSB & 14.94 & 10.7 & 11.72 & 9.56 & 21.6 & 6.148 & 0.0000 & 1.8979 & 0.1805 \\
\hline \multicolumn{10}{|c|}{ MOE } \\
\hline $\mathrm{AA}$ & 2420 & 10.1 & 1983 & 6.23 & 20.5 & 6.520 & 0.0000 & 6.1120 & 0.0209 \\
\hline BB & 2764 & 6.17 & 2244 & 13.93 & 18.8 & 5.339 & 0.0000 & 5.1797 & 0.0321 \\
\hline $\mathrm{CC}$ & 2805 & 5.86 & 2413 & 9.21 & 14.0 & 5.024 & 0.0000 & 2.2540 & 0.1463 \\
\hline DD & 3172 & 6.88 & 2738 & 8.59 & 13.2 & 4.439 & 0.0002 & 0.0903 & 0.7664 \\
\hline $\mathrm{EE}$ & 2920 & 5.15 & 2598 & 7.97 & 11.0 & 4.457 & 0.0002 & 2.6639 & 0.1157 \\
\hline OSB & 2245 & 11.5 & 2049 & 7.58 & 8.7 & 2.410 & 0.0236 & 2.4212 & 0.1323 \\
\hline
\end{tabular}

The current value of the linear dimensions of wood-based materials is a function of its current moisture content. A level of moisture content achieved by a given wood-based material at a given level of air relative humidity is a product of many factors, including the level of securing the given material against moisture effects, resin type, glue treatment level, or even parameters of the pressing process. When conditioning wood-based materials, even in specialist conditioning devices, it should be taken into account that not all samples are treated in exactly the same way, i.e., with identical relative air humidity.

Thus, before evaluating the changes in the sample length, a detailed analysis of the moisture content after each conditioning step was conducted. The results of the two-way ANOVA test for the moisture content are shown in Table 5. Table 5 presents mean values with results of a Tukey's range test, which is a statistical evaluation for finding significance in the differences in the mean values for the major and minor axes of the board and for finding a difference between the maximum and minimum moisture content value at a given moisture content level $(\triangle \mathrm{MC})$. The moisture content of the boards manufactured in the laboratory was $c a .2 .5 \%$. The board manufactured of fine chips was characterized by a slightly higher increase in moisture content of only by a $0.3 \%$ increase. Thus, it should be assumed that at the adapted level of significance $(\alpha=0.05)$, the manufactured boards were characterized by different moisture content levels $(\mathrm{F}(4,159)=8.1098, \mathrm{p}=0.0000$. $)$. Also, the conditioned boards were characterized by very small differences in their moisture content. 
Table 5. Moisture Content of Boards Used During Evaluation of Linear Dimensions

\begin{tabular}{|c|c|c|c|c|c|c|c|}
\hline \multirow{2}{*}{ Board type } & \multicolumn{7}{|c|}{ Relative Humidity of the air (\%) and (Step) } \\
\hline & $20^{*}(1)$ & $30(2)$ & $65(4)$ & $85(5)$ & $65(6)$ & $30(8)$ & $20^{* *}(10)$ \\
\hline \multicolumn{8}{|c|}{ Along } \\
\hline AA & $\begin{array}{c}2.522 \\
a, b\end{array}$ & $\begin{array}{c}4.150 \\
a\end{array}$ & $\begin{array}{c}10.232 \\
a\end{array}$ & $\begin{array}{c}14.673 \\
a\end{array}$ & $\begin{array}{c}10.843 \\
b, c\end{array}$ & $\begin{array}{c}7.784 \\
b\end{array}$ & $\begin{array}{c}3.352 \\
a-c\end{array}$ \\
\hline BB & $\begin{array}{c}2.797 \\
b\end{array}$ & $\begin{array}{c}4.621 \\
b\end{array}$ & $\begin{array}{c}10.608 \\
a-c\end{array}$ & $\begin{array}{c}14.994 \\
a, b\end{array}$ & $\begin{array}{c}11.332 \\
a-c\end{array}$ & $\begin{array}{c}8.600 \\
a\end{array}$ & $\begin{array}{c}3.546 \\
a, b\end{array}$ \\
\hline $\mathrm{CC}$ & $\begin{array}{c}2.413 \\
a\end{array}$ & $\begin{array}{c}4.290 \\
a\end{array}$ & $\begin{array}{c}10.945 \\
a-e\end{array}$ & $\begin{array}{c}14.805 \\
a, b\end{array}$ & $\begin{array}{c}10.747 \\
b\end{array}$ & $\begin{array}{c}8.057 \mathrm{~b}, \\
c\end{array}$ & $\begin{array}{c}3.477 \\
a-c\end{array}$ \\
\hline DD & $\begin{array}{c}2.562 \\
a, b\end{array}$ & $\begin{array}{c}4.594 \\
b\end{array}$ & $\begin{array}{c}10.986 \\
\text { a-e }\end{array}$ & $\begin{array}{c}15.241 \\
a, b\end{array}$ & $\begin{array}{c}11.361 \\
a-c\end{array}$ & $\begin{array}{c}8.526 \\
a, d\end{array}$ & $\begin{array}{c}3.470 \\
a-c\end{array}$ \\
\hline EE & $\begin{array}{c}2.441 \\
a\end{array}$ & $\begin{array}{c}4.266 \\
a\end{array}$ & $\begin{array}{c}11.665 \\
\mathrm{e}\end{array}$ & $\begin{array}{c}15.097 \\
a, b\end{array}$ & $\begin{array}{c}11.567 \\
a-c\end{array}$ & $\begin{array}{c}8.019 \\
b, c\end{array}$ & $\begin{array}{c}3.370 \\
a-c\end{array}$ \\
\hline OSB & - & $\begin{array}{c}4.834 \\
C\end{array}$ & $\begin{array}{c}10.793 \\
a-e\end{array}$ & $\begin{array}{c}15.457 \\
a, b\end{array}$ & $\begin{array}{c}12.125 \\
a\end{array}$ & $\begin{array}{c}8.226 \\
c, d\end{array}$ & $\begin{array}{c}3.507 \\
a-c\end{array}$ \\
\hline \multicolumn{8}{|c|}{ Across } \\
\hline AA & $\begin{array}{c}2.494 \\
a, b\end{array}$ & $\begin{array}{c}4.212 \\
a\end{array}$ & $\begin{array}{c}11.327 \\
b-e\end{array}$ & $\begin{array}{c}15.635 \\
b\end{array}$ & $\begin{array}{c}11.689 \\
a, c\end{array}$ & $\begin{array}{c}8.012 \\
b, c\end{array}$ & $\begin{array}{c}3.540 \\
a, b\end{array}$ \\
\hline BB & $\begin{array}{c}2.801 \\
b\end{array}$ & $\begin{array}{c}4.605 \\
b\end{array}$ & $\begin{array}{c}11.502 \\
c-e\end{array}$ & $\begin{array}{c}15.601 \\
a, b\end{array}$ & $\begin{array}{c}11.237 \\
a-c\end{array}$ & $\begin{array}{c}8.722 \\
a\end{array}$ & $\begin{array}{c}3.555 \\
a, b\end{array}$ \\
\hline $\mathrm{CC}$ & $\begin{array}{c}2.529 \\
a, b\end{array}$ & $\begin{array}{c}4.289 \\
a\end{array}$ & $\begin{array}{c}11.573 \\
d, e\end{array}$ & $\begin{array}{c}15.599 \\
a, b\end{array}$ & $\begin{array}{c}11.611 \\
a, c\end{array}$ & $\begin{array}{c}7.992 \\
b, c\end{array}$ & $\begin{array}{c}3.439 \\
a-c\end{array}$ \\
\hline DD & $\begin{array}{c}2.519 \\
a, b\end{array}$ & $\begin{array}{c}4.618 \\
b\end{array}$ & $\begin{array}{c}10.998 \\
\text { a-e }\end{array}$ & $\begin{array}{c}14.876 \\
\text { a, b }\end{array}$ & $\begin{array}{c}10.732 \\
b\end{array}$ & $\begin{array}{c}8.468 \\
a, d\end{array}$ & $\begin{array}{c}3.303 \\
a, c\end{array}$ \\
\hline EE & $\begin{array}{c}2.504 \\
a, b\end{array}$ & $\begin{array}{c}4.260 \\
a\end{array}$ & $\begin{array}{c}10.459 \\
a, b\end{array}$ & $\begin{array}{c}15.053 \\
a, b\end{array}$ & $\begin{array}{c}11.443 \\
a-c\end{array}$ & $\begin{array}{c}8.773 \\
a\end{array}$ & $\begin{array}{c}3.589 \\
b\end{array}$ \\
\hline OSB & - & $\begin{array}{c}4.835 \\
\mathrm{C} \\
\end{array}$ & $\begin{array}{c}10.767 \\
\text { a-d }\end{array}$ & $\begin{array}{c}15.356 \\
a, b\end{array}$ & $\begin{array}{c}11.845 \\
a \\
\end{array}$ & $\begin{array}{c}8.425 \\
a, d\end{array}$ & $\begin{array}{c}3.263 \\
c\end{array}$ \\
\hline$p$ & 0.60968 & 0.63302 & 0.03520 & 0.00591 & 0.38471 & 0.0000 & 0.86345 \\
\hline$\Delta \mathrm{MC}$ & 0.388 & 0.685 & 1.433 & 0.962 & 1.393 & 0.989 & 0.326 \\
\hline
\end{tabular}

Although the final moisture content of boards was $c a .1 \%$ higher than the baseline, it should be assumed that the level of changes observed in mechanical properties of the boards was a consequence of the changes occurring in the boards during conditioning and did not arise from differences in the moisture content. The largest differences in the maximum and minimum moisture content in a given batch of boards were observed following conditioning at $65 \% \mathrm{RH}$. Furthermore, statistically significant differences were observed in the moisture content of samples obtained from the minor and the major axes. Since this observation did not apply to the same type of board each time, it should be assumed that the observed changes resulted from the performance of conditioning chambers and the distribution of samples in a chamber rather than from the size of the chips used to produce the outer layers.

The conducted three-way ANOVA indicated that relevant changes in length determined for Set $2\left(\left(\delta 1_{65,30}\right)\right.$ had a $c a .75 \%$ larger than those determined for Set 1 $\left(\delta \mathrm{l}_{65,85}\right)(\mathrm{F}(1,378)=1190.9, \mathrm{p}=0.0000$ for $\alpha=0.05)$. This possibly resulted from the fact 
that following the wetting process, or more precisely, in consequence of resultant stresses, some adhesive and cohesive bonds were already destroyed in the studied material.

A previous study implied that OSB boards were characterized by relatively strong anisotropy of changes in the linear dimensions of the board plane (Mirski et al. 2013). The observed changes in the length were more pronounced in the direction of the major axis than the minor axis. Thus, there was two times more adsorption changes (Fig. 1) and 40\% more desorption changes (Fig. 2).

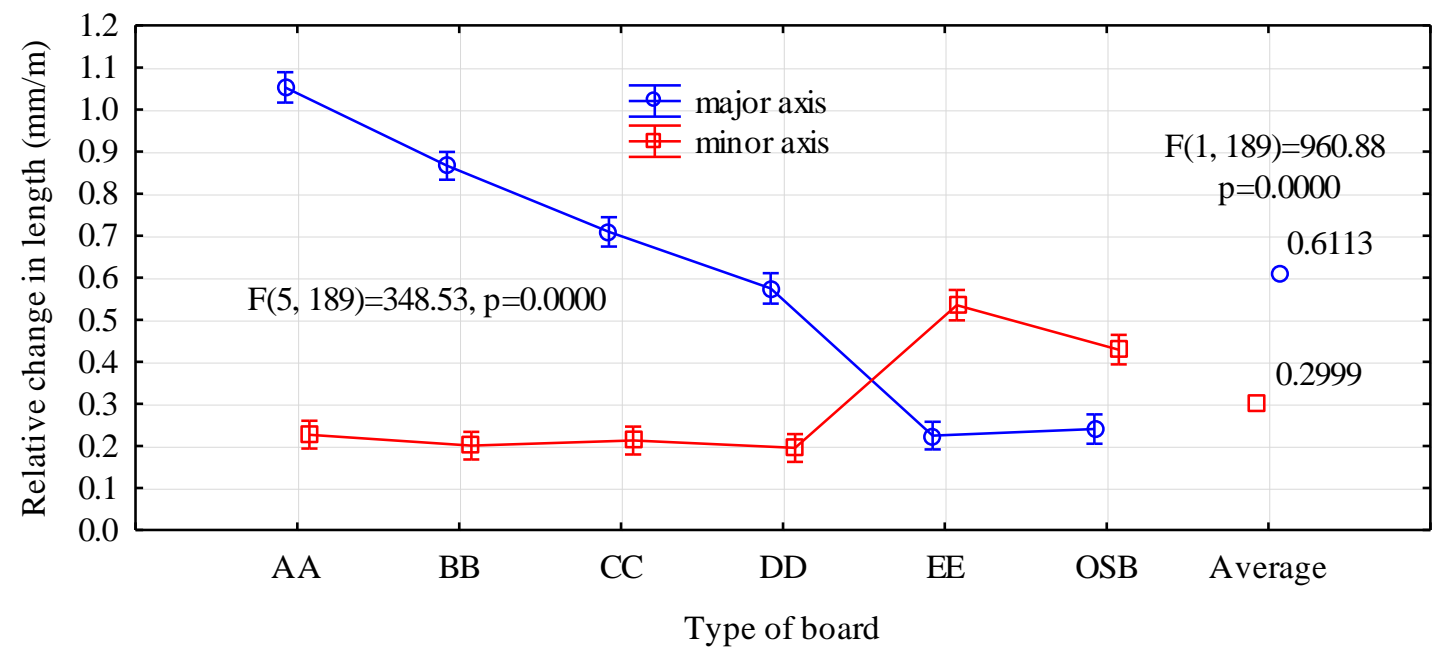

Fig. 1. A chart presenting interactions between types of chips in board outer layers and a direction of sampling for a relative change in the length specified for the Set $1\left(\delta \lambda_{65,85}\right)$

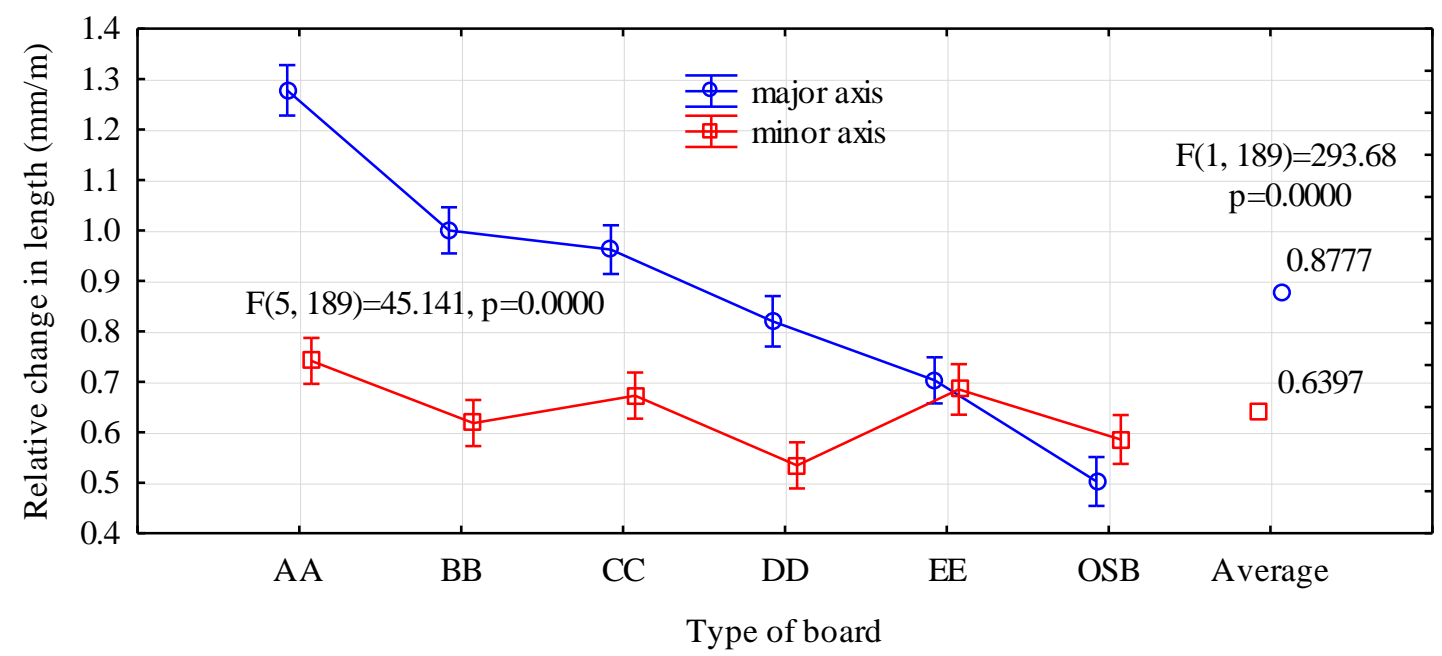

Fig. 2. A chart presenting interactions between types of chips in board outer layers and a direction of sampling for a relative change in the length specified for the Set $2\left(\delta \lambda_{65,30)}\right.$

However, regardless of the direction of changes in the air relative humidity, no relationship was confirmed between the size of the chips in the outer layers and the sampling direction. Relative changes in the length determined for the major axis were smaller than the changes determined for the minor axis only for the OSB board and its laboratory equivalent, which was the EE board. This observation was consistent with earlier studies (Mirski et al. 2013). However, even larger changes, observed up to five times, were observed for the major axis. The perpendicular orientation of wood strips in 
the core layer in relation to the longer sample side, with much finer chips in the outer layer, resulted in an increase in the sample length in a direction of the major axis. In this specific case, the layout of the fibers in the chips in the core layer was perpendicular to the direction of the measured increase in length, and the change in the dimension was associated with a change in the linear dimension in the tangential or radial direction. When chips in the outer layers were much finer, they were more difficult to arrange. Thus, preventing an increase in the length of chips in the core layer was not possible. Although in terms of mechanical properties, already the DD board was characterized by an orientation index (a ratio of MOR(MOE)II to MOR(MOE) $\perp$ ) close to one, yet to counterbalance length deformations in both identified axes, the chips used in the outer layers should have similar dimensions to those used in the core layer. Therefore, the changes in the relative length of boards occurring in the mechanically weaker board axis increased with a reduction in the size of chips forming its outer layers. On the contrary, in the other direction, which is the other axis, relative changes in the length were similar. For this reason, higher values of relative changes in the length were analyzed more thoroughly, regardless of the axis they involved, i.e. the changes determined for the major axis in AA-DD boards, and for the minor axis in EE board. Regardless of the direction of the changes in the air relative humidity, none of the most common (linear, exponential, and logarithmic) relationships used in the research could be established between relative changes in the length and the relative change in the static bending strength or the relative modulus of elasticity. In general, the larger the changes in the length during changes in the board moisture content, the more pronounced the drop in these properties. It means that boards with outer layers produced of finer chips were more susceptible to loss of their mechanical properties, expressed as the bending strength, during changes in their moisture content.

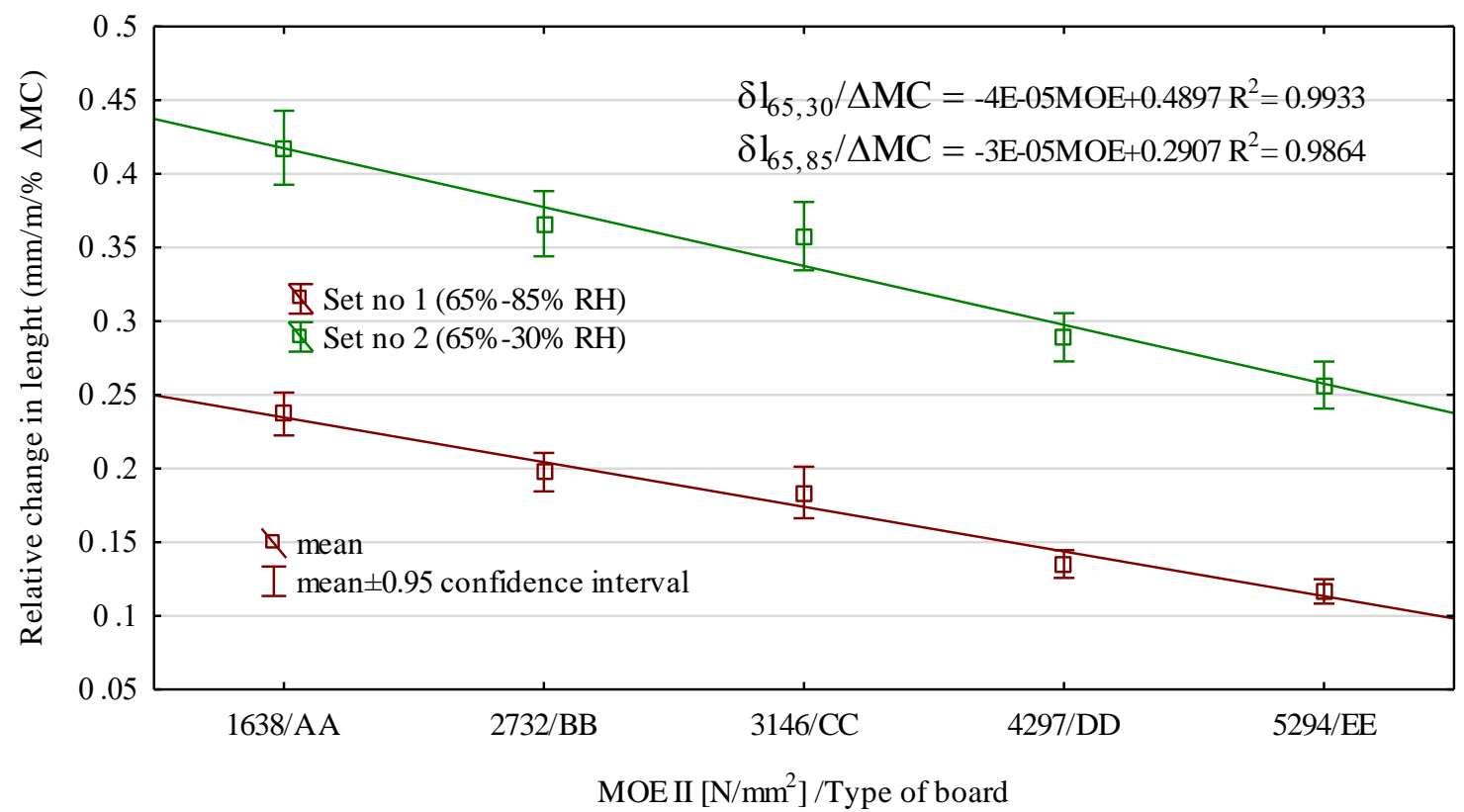

Fig. 3. The relationship between modulus of elasticity and a higher value of a relative change in the length of board, calculated as a change in humidity between 4 and 5 (Set 1) or between 6 and 8 (Set 2) steps of sample conditioning

As the extent of observed changes in the linear dimension strongly correlated with changes in humidity, the determined values of the relative change in the length were divided by a change in the moisture content determined for the boards when passing 
between the evaluated steps. When the moisture content was taken into account during evaluation of the relative changes in the length, the values observed for individual boards were equalized (Fig. 3). This applies, in particular, to the changes observed for the Set 1. In this case it should be assumed that changes in the length were similar in DD and EE boards (Tukey's test, $\mathrm{p}=0.2425$ ), ca. 50\% larger in CC and DD boards (Tukey's test, $\mathrm{p}=$ 0.5420), and they were the largest in the board with outer layers made of microchips. Furthermore, as a result of these calculations, a high linear correlation was established between observed changes in the length and the modulus of elasticity determined for the major axis of the boards. The linear relationship occurred both for absorption and desorption changes alike. A susceptibility to deformation caused by moisture in a more susceptible axis of boards manufactured this way was therefore inversely proportional to the modulus of elasticity specified for the larger axis (Fig. 3).

\section{CONCLUSIONS}

1. The reduction in the mechanical properties increased with a reduction in the size of chips forming the outer layers. Relative changes in the static bending strength and the modulus of elasticity were $c a$. $20 \%$ and $60 \%$ larger, respectively, when determined for the major axis of the board than that of the minor axis.

2. Relative changes in the length determined for the first set (wetting process), was ca. $60 \%$ larger than those specified for the second set (drying process). The main factors responsible for this situation were changes observed for the minor axis of the boards; relative changes in length for Set 2 were at most three times larger than those determined for Set 1.

3. The axis of the board where the wood strips were perpendicular to the sample length, could deform more freely and were more susceptible to deformations. This axis was the major one in the boards of finer chips (AA-DD), and the minor one in the boards of wood strips $(\mathrm{EE})$.

4. The finer chips used to form the outer layers, the more susceptible boards to deformations.

5. There was a linear relationship between relative changes in the board length determined for the axis more susceptible to deformation and the modulus of elasticity. These changes were inversely proportional to the value of the modulus of elasticity.

\section{ACKNOWLEDGMENTS}

The authors are grateful to Mr. Krzysztof Pajor (alumnus) for his help with determining some properties of the manufactured boards.

\section{REFERENCES CITED}

Andersen, A. W., and Troughton, G. E. (1996). "New phenolic formulations for bonding higher moisture content OSB panels," Forest Products Journal 46(10), 72-76.

Avramidis, S., and Smith, L. A. (1989). "The effect of resin content and face-to-core ratio 
on some properties of OSB," Holzforschung 43(2), 131-133.

Brinkmann, E. (1979). "OSB-Platten, ihre Eigenschaften, Verwendung und Herstellungstechnologie," Holz Roh Werkst 37, 139-142. DOI: 10.1007/BF02610844

Brochmann, J., Edwardson, C., and Shmulsky, R. (2004). "Influence of resin type and flake thickness on properties of OSB," Forest Products Journal 54(3), 51-55.

EN 300 (2006). "Oriented strand boards (OSB) - Definitions, classification and specifications," European Committee for Standardization, Brussels, Belgium.

EN 310 (1993). "Wood-based panels - Determination of modulus of elasticity in bending and of bending strength," European Committee for Standardization, Brussels, Belgium.

EN 318 (2002). "Wood-based panels - Determination of dimensional changes associated with changes in relative humidity," European Committee for Standardization, Brussels, Belgium.

Geimer, R. L., Montrey, H. M., and Lehmann, W. F. (1975). "Effects of layer characteristics on the properties of three-layer particleboards," Forest Products Journal 25(3), 19-29.

Gündüz, G., Yapici, F., Özçifçi, A., and Kalaycioğlu, H. (2011). "The effects of adhesive ratio and pressure time on some properties of oriented strand board," BioResources 6(2), 2118-2124.

Han, G., Wu, Q., and Lu, J. Z. (2006). "Selected properties of wood strand and oriented strandboard from small diameter southern pine trees," Wood and Fiber Science 38(4), 621-632.

Han, G., Wu, Q., and Duan, X. (2005). "Physical and mechanical properties of mixed command and hardwood oriented strandboard bonded with phenol-formaldehyde resin," Forest Products Journal 55(10), 28-36.

Han, G., Wu, Q., and Lu, J. Z. (2007). "The influence of fines content and panel density on properties of mixed hardwood oriented strandboard," Wood and Fiber Science 39(1), 2-15.

Kim, M. G., and Strickland, R. (1994). "Adhesive properties of furfural-modified phenolformaldehyde resins as oriented standboard binders," Holzforschung 48(3), 262-267. DOI: $10.1515 /$ hfsg.1994.48.3.262

Kim, M. G., and Watt, R. C. (1996). "Effect of urea addition to phenol-formaldehyde resin binders for oriented strandboard," Journal of Wood Chemistry and Technology 16(1), 21-34. DOI: 10.1080/02773819608545780

Mayers, K. L. (2001). Impact of Strand Geometry and Orientation on Mechanical Properties of Strand Composites, Master's Thesis, Washington State University, Pullman, WA, USA.

Mirski, R., and Dziurka, D. (2011a). "Applicability of strand substitution in the core of OSB," BioResources 6(3), 3080-3086.

Mirski, R., and Dziurka, D. (2011b). "The utilization of chips from comminuted wood waste as a substitute for flakes in the oriented strand board core," Forest Products Journal 61(6), 473-478. DOI: 10.13073/0015-7473-61.6.473

Mirski, R., Derkowski, A., and Dziurka, D. (2013). "Dimensional stability of OSB panels subjected to variable relative humidity: Core layer made with fine wood chips," BioResources 8(4), 6448-6459. DOI: 10.15376/biores.8.4.6448-6459

Mirski, R., Dziurka, D., and Derkowski, A. (2012). "Application of chips designed for particleboard core in OSB as substitute for flakes," Lignocellulose 1(1), 22-32.

Mirski, R., Dziurka, D., and Derkowski, A. (2016). "Properties of oriented strand boards with external layers made of non-strand chips," BioResources 11(4), 8344-8354. 
DOI: 10.15376/biores.11.4.8344-8354

Sellers Jr., T. (2001). "Wood adhesive innovations and applications in north America," Forest Products Journal 51(6), 12-22.

Semple, K. E., Sackey, E. K., Fakhri, H. R., McConchie, T., and Smith, G. D. (2006). "Effect of extended mat open assembly time on properties of OSB bonded with pMDI," Wood and Fiber Science 38(3), 546-552.

$\mathrm{Wu}, \mathrm{Q}$., and Lee, J. N. (2002). "Thickness swelling of oriented strandboard under longterm cyclic humidity exposure condition," Wood and Fiber Science 34(1), 125-139.

Wu, Q., and Piao, C. (1999). "Thickness swelling and its relationship to internal bond strength loss of commercial oriented strandboard," Forest Products Journal 49, (7/8), 50-55.

Wu, Q., and Suchsland, O. (1996). "Linear expansion and its relationship to moisture content change for commercial oriented strandboards," Forest Products Journal 46, (11/12), 79-83.

Wu, Q. (1999). “In-plane dimensional stability of oriented strand panel: effect of processing variables," Wood and Fiber Science 31(1), 28-40.

Article submitted: May 25, 2017; Peer review completed: July 15, 2017; Revised version received and accepted: July 24, 2017; Published: August 14, 2017.

DOI: $10.15376 /$ biores.12.4.7107-7117 